\title{
Molecular regulation and genetic improvement of seed oil content in Brassica napus $L$.
}

\author{
Wei HUA, Jing LIU, Hanzhong WANG (ه) \\ Key Laboratory of Biology and Genetic Improvement of Oil Crops, Ministry of Agriculture, Oil Crops Research Institute, Chinese Academy \\ of Agricultural Sciences, Wuhan 430062, China
}

\begin{abstract}
As an important oil crop and a potential bioenergy crop, Brassica napus L. is becoming a model plant for basic research on seed lipid biosynthesis as well as seed oil content, which has always been the key breeding objective. In this review, we present current progress in understanding of the regulation of oil content in $B$. napus, including genetics, biosynthesis pathway, transcriptional regulation, maternal effects and QTL analysis. Furthermore, the history of breeding for high oil content in B. napus is summarized and the progress in breeding ultra-high oil content lines is described. Finally, prospects for breeding high oil content $B$. napus cultivars are outlined.
\end{abstract}

Keywords breeding, maternal effects, oilseed rape, QTL

\section{Introduction}

Oil is one of the three major nutrients required for human survival. As the third major source of edible oil after soybean and palm, Brassica napus L. (rapeseed) accounts for about $15 \%$ of the world total production ${ }^{[1]}$. Highquality $B$. napus oil, with low saturated fatty acid content, is considered as one of the healthiest edible vegetable oils. B. napus is mainly produced in Asia, North America, and Europe, where its production accounts for $31 \%, 24 \%$ and $32 \%$, respectively, of world total production in 2015, according to data from the USDA Foreign Agricultural Service (World Agricultural Production: http://www.fas. usda.gov/data/world-agricultural-production). The two main rapeseed producing countries in Asia are China and India. In China, the rapeseed cultivation area of about 7

Received May 17, 2016; accepted June 16, 2016

Correspondence: wanghz@oilcrops.cn million hectares yearly accounts for about $21 \%$ of the total world production. Rapeseed oil is also the largest domestic source of edible vegetable oil in China (http://www.fas. usda.gov/data/world-agricultural-production).

Oil production is the primary target trait of rapeseed breeding. Rapeseed oil production efficiency is determined by seed oil content and seed yield ${ }^{[2]}$. These two factors are therefore important breeding objectives for improving oil production. Traditional breeding for over 60 years in China has increased the seed yield 2-3-fold compared to initially introduced rapeseed varieties that yielded about $750 \mathrm{~kg} \cdot \mathrm{hm}^{-2[3]}$. Recent studies suggest that increased oil content may be a more efficient approach to increase oil production per unit area; an increase in oil content by $1 \%$ was estimated to be equivalent to increasing the seed yield by $2 \%-3 \%[4]$. Therefore, efforts to understand the regulatory basis of oil content and to breed high oil content varieties are objectives of current rapeseed research. With the development of biotechnology, the wide application of second-generation technology and SNP markers has greatly promoted the study of rapeseed oil content in the world. Especially in China, rapeseed oil content research and breeding have made good progresses in recent years, and the details are described in the following sections.

\section{Regulation of $B$. napus oil content}

\subsection{Genetic analysis on seed oil content in B. napus}

Plant seeds are complex structures that consist of three major components: the embryo, the endosperm, and the seed coat. In mature rapeseed seeds, the endosperm degenerates and the seed coat enwraps the embryo tightly. Based on the results from $\mathrm{Hu}$ et al. ${ }^{[5]}$, most of the oil body organelle accumulates in the embryo and a small proportion of oil body was also observed in the aleuronic 
cells of the seed coat. Seed oil content is a complex quantitative trait controlled by multiple genes that undergo complex interactions with the environment. Genetic control involves a combination of seed embryo genetic effects, and maternal nuclear and cytoplasmic genetic effects. The genetic effects on seed oil content vary because of different research methods and materials. Gan and $\mathrm{Lin}^{[6]}$ showed that seed oil content in B. napus was influenced by maternal genotype, whereas Wang ${ }^{[7]}$ found that the oil content in hybrids was affected by embryo genotype as well as the maternal genotype. Another study by Wu et al. ${ }^{[8]}$ indicated that oil content was determined by embryo genotype, cytoplasmic and maternal genotype effects, and interaction of genotype and environment. The above results suggest that studies in different genetic backgrounds might be able to detect one effect but detection of others might be limited. To avoid the influence of genetic background, Wang et al. ${ }^{[9]}$ chose 10 representative lines with different oil contents from 3000 B. napus accessions to perform a genetic analysis. They found that the maternal genotype contribution to average oil content was as high as $86 \%$, and that the xenia effect accounted for only $14 \%$. Moreover, by comparison of oil contents between reciprocal $F_{1}$ and $F_{2}$ populations, cytoplasmic effects were also found to have an important influence on oil content ${ }^{[9]}$.

\subsection{The effects of the embryo oil synthesis process on seed} oil content

Oil synthesis in plant seeds is a complex physiological and biochemical process involving two steps: fatty acid synthesis (FAS), and triglyceride (TAG) accumulation. The biochemical pathways of the two processes have been well studied ${ }^{[10-12]}$. The key genes encoding lipid synthesis and regulation have been successfully cloned and characterized in Arabidopsis including glycolysis-related genes and fatty acid synthesis-related gene ACCase (Acetyl-CoA carboxylase) ${ }^{[13]}$, G3PDH (sn-Glycerol-3phosphate dehydrogenase ${ }^{[14]}$, TAG biosynthesis genes DGAT1 (diacylglycerol acyltransferase 1$)^{[15-17]}$ and DGAT2 (diacylglycerol acyltransferase 1) ${ }^{[18]}$, GPAT (glycerol-3-phosphate acyltransferase) $^{[19]}$, and LPAAT (lysophosphatidic acid acyltransferase) $^{[20,21]}$. Genetic transformation studies confirmed that these genes can increase seed oil content to various degrees ${ }^{[22]}$. For example, seed obtained from transgenic B. napus expressing the cytosolic ACCase in the plastid resulted in a relative increase in oil content of $5 \%{ }^{[13]}$; overexpression of a mutated yeast sn-2 acyltransferase gene (SLC1-1) in B. napus and Arabidopsis induced the mature seed from the various transgenic lines to produce relative increases in oil content ranging from $8 \%$ to $48 \%{ }^{[20]}$; Tropaeolum majus DGAT1 (TmDGAT1) has also been overexpressed in higherucic acid $B$. napus resulting in relative seed oil content increases of $11 \%-30 \%{ }^{[23]}$.
The flow of carbon into storage lipid is also influenced by other metabolic pathways which draw upon cellular carbon. In plants, glycolysis takes place in the cytosol and plastid, with both compartments linked by transporters in the plastidial envelope ${ }^{[24]}$. Pyruvate kinase catalyzes the irreversible production of pyruvate and ATP, which are utilized in numerous biochemical pathways. Andre et al. ${ }^{[25]}$ disrupted the gene encoding the $\beta 1$ subunit of plastidial heteromeric pyruvate kinase complex in Arabidopsis which resulted in mature seed displaying a $60 \%$ reduction in seed oil content. Mitochondrial pyruvate dehydrogenase kinase (PDHK) downregulates the mitochondrial PDH complex by phosphorylation. Seed-specific antisense repression of the gene encoding mitochondrial PDHK during seed maturation has been shown to result in increased seed oil content and seed weight in Arabidopsis ${ }^{[26,27]}$. Wakao et al. ${ }^{[28]}$ have suggested that cytosolic Glu6PDH plays a role in provision of reducing power (in the form of NADPH) for fatty acid (FA) biosynthesis in maturing seeds where photosynthesis may be restricted.

Certain transcription factors regulate lipid synthesis pathway genes and can greatly influence metabolic processes involved in seed oil accumulation. In Arabidopsis and rapeseed, there are five such transcription factors that control downstream target genes, namely WRI1, LEC1, LEC2, ABI3, and FUS3 ${ }^{[29]}$. WRI1 encodes an AP2/EREB domain transcription factor; the wril mutant cannot convert sucrose into precursors for fatty acids, leading to increased insoluble sugar contents and reduced seed oil content ${ }^{[30,31]}$. Overexpression of rapeseed WRII in Arabidopsis increased not only seed oil content but also seed weight ${ }^{[32]}$. LEC1, encoding CCAAT-box binding factor HAP3 subunit homolog plays an important role in the formation and maturation of the seed embryo ${ }^{[33,34]}$. Overexpression of LEC1 in rapeseed upregulates many key genes that are involved in glycolysis, lipid synthesis, and oil accumulation, leading to a significant increase in fatty acid levels ${ }^{[35]}$. LEC2, ABI3, and FUS3 belong to plantspecific transcription factor families. The transcription level of the $L E C 2$ gene was positively correlated with oil accumulation ${ }^{[36-38]}$. FUS3 and $A B I 3$ have important roles in late-stage seed development ${ }^{[39]}$. TRANSPARENT TESTA2 (TT2), regulating biosynthesis of proanthocyanidins (PAs) in the seed coat of Arabidopsis causes inhibition of fatty acid (FA) biosynthesis in the seed embryo. TT2 is expressed in embryos at an early developmental stage; it directly binds to the regulatory region of FUSCA3 (FUS3) and mediates expression of numerous genes in the FA biosynthesis pathway ${ }^{[40]}$. These genes and their respective functions are summarized in Table 1.

\subsection{Maternal effects on seed oil accumulation}

Maternal effect refers to the effect that the cultivar genotype and the environmental response of the maternal 
Table 1 Identification and function of genes affecting seed oil content

\begin{tabular}{|c|c|c|c|c|}
\hline Organ & Function & Gene & Specie & Reference No \\
\hline \multirow[t]{13}{*}{ Embryo } & Fatty acid synthesis & Acetyl-CoA carboxylase (ACCase) & Arabidopsis & [13] \\
\hline & \multirow[t]{5}{*}{ TAG synthesis } & Acyl-CoA:sn-glycerol-3-phosphate acyltransferase (GPAT) & Arabidopsis & [19] \\
\hline & & sn-Glycerol-3-phosphate dehydrogenase (G3PDH) & Rapeseed & [14] \\
\hline & & Acyl-CoA:lysophosphatidic acid acyltransferase (LPAAT) & Arabidopsis, rapeseed & {$[20,21]$} \\
\hline & & Type 1 acyl-CoA: diacylglycerol acyltransferase (DGAT1) & Arabidopsis, rapeseed, maize & {$[15,16]$} \\
\hline & & Type 2 acyl-CoA: diacylglycerol acyltransferase (DGAT2) & Soybean & [18] \\
\hline & \multirow[t]{3}{*}{ Glycolysis related } & Mitochondrial pyruvate dehydrogenase kinase (PDHK) & Arabidopsis, rapeseed & {$[26,27]$} \\
\hline & & Cytosolic D-glucose-6-phosphate dehydrogenase (Glu6PDH) & Arabidopsis & {$[28]$} \\
\hline & & Plastidial heteromeric pyuvate kinase complex & Arabidopsis & {$[25]$} \\
\hline & \multirow[t]{4}{*}{ Transcription regulation } & Leafy contyledon 1 (LEC1) & Arabidopsis, rapeseed, maize & {$[34,35,37]$} \\
\hline & & Leafy contyledon 2 (LEC2) & Arabidopsis & {$[36]$} \\
\hline & & Transparent tetsa 2(TT2) & Arabidopsis & {$[40]$} \\
\hline & & Wrinkled 1(WRI1) & Arabidopsis, rapeseed, maize & {$[30,32,37]$} \\
\hline \multirow[t]{3}{*}{ Seed coat } & \multirow{3}{*}{$\begin{array}{l}\text { Seed size regulating genes in } \\
\text { embryo }\end{array}$} & Apetala 2 (AP2) & Arabidopsis & [41] \\
\hline & & CYP78A5 (KLU) & Arabidopsis & {$[42]$} \\
\hline & & Transparent testa 8 (TT8) & Arabidopsis & [43] \\
\hline Mother plant & Photosynthesis & Growth-regulating factor 2 (GRF2) & Rapeseed & [44] \\
\hline All & Cytoplast effect & ORF188, a mitochondrial gene & Rapeseed & {$[45]$} \\
\hline
\end{tabular}

parent have on traits of the offspring ${ }^{[46]}$. The seeds of rapeseed develop and mature within maternal tissue surrounded by the maternal silique wall (Fig. 1). The development of the embryo depends on the direct supply of nutrients from the plant, hence the physiological metabolism and gene expression in the silique wall or seed coat (maternal tissue) can influence the accumulation of seed nutrients (Fig. 1). Wang et al. ${ }^{[9]}$ showed that the maternal plant genotype controls the oil content of $B$. napus $\mathrm{F}_{1}$ seeds. After flowering, the green silique wall becomes a major organ for photosynthesis, and provides more than $70 \%$ of the energy for seed development ${ }^{[47,48]}$.

Thanks to high-throughput sequencing and transcriptome gene expression analysis, studies with rapeseed lines zy036 and 51070 have confirmed that the silique wall photosynthesis regulates accumulation of seed oil ${ }^{[49]}$. Seed coat-specific gene expression can regulate the supply of nutrients and influence the maturation process, affecting the final development of the endosperm and embryo ${ }^{[50-52]}$. For example, $A P 2$ and $K L U$ regulate glucose metabolism, and affect the seed oil content in the Arabidopsis seed coat $^{[41,42,53]}$. Tissue culture studies using rapeseed siliques, ovules and embryos from rapeseed lines with different oil content have confirmed that seed coat affects oil accumulation by regulating sucrose concentration ${ }^{[44,54]}$. TRANSPARENT TESTA 8 (TT8) in the seed coat was also reported to act maternally to affect seed FA biosynthesis and inhibited seed FA accumulation by downregulating a group of genes including $L E C 1, L E C 2$, $F U S 3$, and $C D S 2$, which are transcriptional factors important for seed development or FA biosynthesis ${ }^{[43]}$. Wang et al. ${ }^{[9]}$ showed that the cytoplasm significantly regulates rapeseed oil content in lines 51218 and 56366. Cytoplasmic genome sequencing of these two lines led to the development of useful molecular markers ${ }^{[55]}$. Cytoplasmic effect and marker linkage analysis between the two materials and resource populations helped to identify the key gene $(O R F 188)$ that affect oil content ${ }^{[45]}$. The locations of the molecular regulation pathways are indicated in Fig. 1.

\subsection{QTL mapping on seed oil content}

Seed oil content is a complex quantitative trait controlled by multiple genes; therefore, high oil content $B$. napus lines from different sources show significant genetic variations. In the past 20 years, researchers have used DH populations, recombinant inbred lines and $F_{2}$ populations from parents with different oil contents to locate genes/QTLs affecting oil content. A large number of QTLs have been identified across almost all chromosomes, with each study identifying 3-27 loci ${ }^{[56-66]}$. For example, Qiu et al. ${ }^{[58]}$ localized QTLs in a DH population to linkage groups N1, N3, N4, N8, N12, N13, and N17. Delourme et al. ${ }^{[59]}$ located 14 and 10 QTL regions in two DH populations. The genetic basis of rapeseed oil content has also been studied using correlation analysis. Five years ago, most of the maps were constructed on the basis of the SSR markers. With the development of the GWAS, the QTLs maps depend on it more and more. For example, Zou 


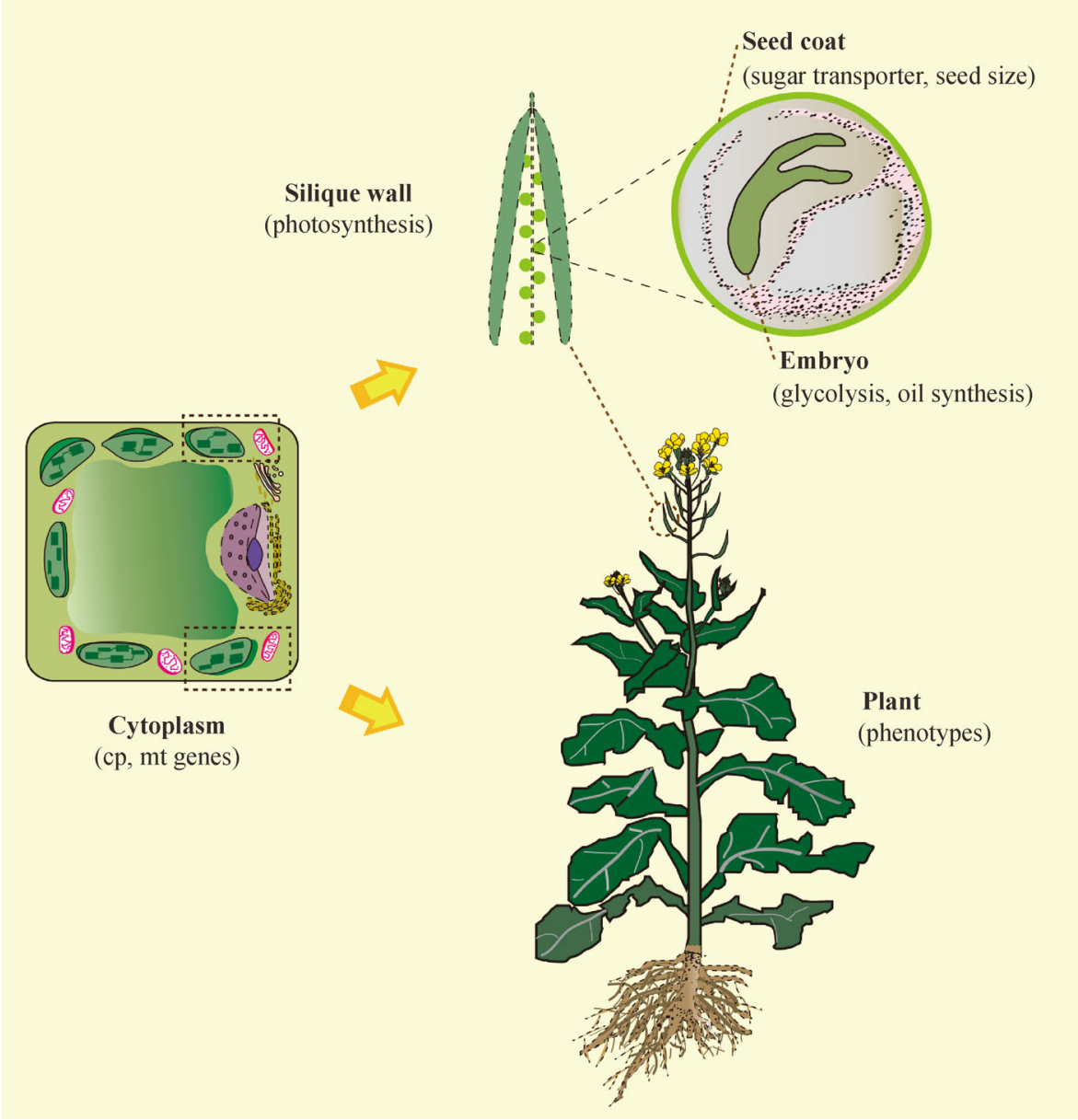

Fig. 1 Regulation model of seed oil content in Brassica napus. Boldfaces indicate major organs or factors controlling the seed oil content and their relative regulating pathways are listed in the parenthesis.

et al. ${ }^{[67]}$ used 116 molecular markers linked to oil content QTL to conduct a GWAS analysis on 172 rapeseed lines from around the world. Their study indicated that about $50 \%$ of the markers were correlated with oil content. Sun et al. ${ }^{[68]}$ analyzed 14 markers for candidate oil synthesis genes with seven major QTL peak areas or within the confidence intervals in 81 rapeseed core germplasm accessions. They found that six markers in four QTL regions were associated with oil content, and that combinations of four of these markers could increase oil content by $5 \%$. Although previous studies found many loci associated with oil content, the phenotypic variability and additive effect of the detected QTLs for oil content were relatively small. As a consequence, there has been little application of markers for oilseed content in rapeseed breeding. Recently, using a Brassica 60K SNP array, three segregating populations with high oil (zy036, 6F313, and 61616 ) and one low oil content (51070) strain were used to identify oil content QTLs where differences in oil content reached $15 \%$. They obtained six QTLs from the three different high oil strains that contributed more than $20 \%$ of the variation which providing a good resource for marker- assisted breeding of high oil rapeseed ${ }^{[69,70]}$. These results are summarized in Table 2.

\subsection{Relationships between oil content and other traits}

As seed oil content and seed yield traits are closely related to each other, clarification of relationships between various traits and oil content is essential for breeding for high oil content. Investigation of the correlation of seed oil content with several major yield traits in 16 varieties suggested positive contributions in the following order: pod number $>$ lodging rate $>1000$ grain weight $>$ yield $>$ main inflorescence fruitless rate $>$ silique number ${ }^{[72]}$. Another study showed that oil content was significantly positively correlated $(r=0.421)$ with seed number per silique while it only had a small positive correlation $(r=0.172)$ with single seed weight ${ }^{[61]}$. The correlation between oil content and inflorescence yield in segregating DH populations varied with geographic location ${ }^{[73]}$. In this work a positive correlation was found between oil content and main inflorescence yield in one location whereas oil content in the other three locations was not significantly correlated 
Table 2 QTLs affecting seed oil content in B. napus

\begin{tabular}{|c|c|c|c|c|c|}
\hline Oil content of parents $/ \%$ & Localization method & QTL number & Position & Contribution/\% & Reference No. \\
\hline $43.60,42.00$ & DHP, ML & 7 & $\mathrm{~N} 1, \mathrm{~N} 3, \mathrm{~N} 4, \mathrm{~N} 8, \mathrm{~N} 12, \mathrm{~N} 13, \mathrm{~N} 17$ & $2.40-15.70$ & [58] \\
\hline $48.00,46.00$ & DHP, ML & 15 & $\mathrm{~N} 1, \mathrm{~N} 2, \mathrm{~N} 3, \mathrm{~N} 5, \mathrm{~N} 6, \mathrm{~N} 10, \mathrm{~N} 12, \mathrm{~N} 13, \mathrm{~N} 15, \mathrm{~N} 16, \mathrm{~N} 17$ & $1.20-13.40$ & [59] \\
\hline $47.50,41.70$ & DHP, ML & 8 & N1, N4, N6, N12, N16, N17, N19 & $1.77-27.57$ & {$[59]$} \\
\hline $43.28,37.03$ & DHP, ML & 5 & N1, N8, N10, N13 & $5.21-10.17$ & [64] \\
\hline $39.70,34.80$ & DHP, ML & 7 & N4, N7, N11, N16, N17 & $3.73-10.46$ & {$[63]$} \\
\hline $39.70,34.80$ & DHP, ML & 9 & $\mathrm{~N} 1, \mathrm{~N} 3, \mathrm{~N} 4, \mathrm{~N} 5, \mathrm{~N} 7, \mathrm{~N} 13, \mathrm{~N} 14$ & $5.19-13.57$ & {$[65]$} \\
\hline N/A & DHP, ML & 19 & $\begin{array}{c}\mathrm{N} 1, \mathrm{~N} 2, \mathrm{~N} 3, \mathrm{~N} 4, \mathrm{~N} 5, \mathrm{~N} 6, \mathrm{~N} 7, \mathrm{~N} 8, \mathrm{~N} 10, \mathrm{~N} 12, \mathrm{~N} 13, \mathrm{~N} 14, \mathrm{~N} 16, \\
\mathrm{~N} 18\end{array}$ & $4.20-30.20$ & [66] \\
\hline $49.53,39.42$ & DHP, ML & 12 & $\mathrm{~A} 2, \mathrm{~A} 3, \mathrm{~A} 5, \mathrm{~A} 6, \mathrm{C} 2, \mathrm{C} 5, \mathrm{C} 8, \mathrm{C} 9$ & $9.15-24.56$ & [69] \\
\hline \multirow{2}{*}{$30.00-52.00$} & NP, GWAS & 12 & $\mathrm{~A} 1, \mathrm{~A} 3, \mathrm{~A} 9, \mathrm{~A} 10, \mathrm{C} 2, \mathrm{C} 3$ & $3.00-15.00$ & {$[67]$} \\
\hline & NP, GWAS & 26 & $\mathrm{~A} 1, \mathrm{~A} 3, \mathrm{~A} 4, \mathrm{~A} 9, \mathrm{~A} 10, \mathrm{C} 2, \mathrm{C} 3$ & $5.00-15.00$ & {$[67]$} \\
\hline $32.66-46.73$ & NP, GWAS & 4 & $\mathrm{~A} 1, \mathrm{~A} 5, \mathrm{~A} 7, \mathrm{~A} 8$ & $4.42-13.13$ & {$[68]$} \\
\hline $34.20-51.40$ & NP, GWAS & 1 & A8 & 6.22 & [71] \\
\hline
\end{tabular}

Note: DHP, DH segregative population; ML, map-based localization; NP, natural population; GWAS, genome-wide association studies.

with inflorescence yield. The study concluded that the oil content and yield did not have a strong negative correlation, thus setting a theoretical foundation for synchronized oil content and yield breeding.

Physiological and biochemical studies showed that Sclerotinia resistance and lodging resistance are important factors affecting oil content in rapeseed ${ }^{[74]}$. With the aid of high-throughput sequencing and transcriptome gene expression analysis, two functional genes (HSP 17.8 and $D D T$ ) were identified in $B$. napus that could stabilize oil content under stress by improving the heat and drought resistance of plants (unpublished data). The above results demonstrated that plant resistance and oil content are positively correlated; thus, providing a theoretical and technical basis for synchronized improvement in B. napus varieties.

\subsection{Relationships between environment and oil content}

As a quantitative trait, rapeseed oil content is controlled by multiple genes and influenced by environmental factors. Because of the wide and varied planting area in China, rapeseed oil contents in diverse ecological areas show great differences. Some studies suggest that most of the QTL loci of the same population detected in different environments were environmentally specific, indicating that the adaption to different environmental factors has an important role in fostering high oil content varieties bearing strong alleles ${ }^{[71]}$. Temperature and light are the two greatest environmental factors influencing oil production of rapeseed ${ }^{[75-77]}$. High temperature during rapeseed maturation is not conducive to the accumulation and transformation of nutrient material into seed ${ }^{[75]}$. Especially in China, in the Yangtze River Basin, which contains the main Chinese Rapeseed producing areas, temperatures often rise too fast. High temperature forces seeds to mature earlier. As a result, seed weight and oil content decrease sharply. Some studies also show adequate lighting and long-time illumination can increase the efficiency of lipid accumulation ${ }^{[76,77]}$. Currently, research on the mechanism whereby environmental factors affect seed oil content is insufficient. Yu et al. ${ }^{[78]}$ analyzed the global transcription profiles of $20 \mathrm{~d}$-old siliques of $B$. napus after heat stress using a Brassica 95K EST microarray and found that many HSF/HSP transcripts and other heat-related marker genes were upregulated. Other upregulated genes including some transcription factors and potential developmental regulators were preferentially expressed in the heat-stressed silique wall or seed.

\section{Progress and prospects for genetic improvement of oil content in $B$. napus}

\subsection{Creation of ultra-high oil B. napus resources}

Breeding high oil rapeseed varieties ten years ago largely depended on conventional plant breeding methods such as continuous individual plant selection in varietal populations, hybrids between varieties, mutagenesis, yellow seed, and heterosis. For example, in 2007, Dr. Fu Tingdong at Huazhong Agricultural University bred high oil (up to $54.72 \%$ ) and double low rapeseed line by hybridization and a series of selections ${ }^{[79]}$. Using similar technology, $\mathrm{Fu}$ et al. ${ }^{[80]}$ at the Chinese Jiangshu Academy of Agricultural Sciences used a high oil content population as the selection group to positively screen for seed oil content and obtained a high oil line HOC3 with an oil content of $54.52 \%$.

In recent years, conventional breeding methods to improve oil content in rapeseed have encountered increasing bottlenecks. More biotechnology approaches, such as microspore culture and molecular marker-assisted 
selection breeding are urgently needed to support high oil content breeding. Zhu et al. ${ }^{[81]}$ reported that a combination of gene pyramiding and microspore culture helped to increase oil content to $52.38 \%$ in the restorer material strain T057-7. Li et al. ${ }^{[82]}$, at the Shanxi Provincial Hybrid Rapeseed Research Center, increased the oil content of B. napus germplasm materials from about $40 \%-61.7 \%$ using single crosses, backcrosses, ecological breeding, yellow seed breeding and DH line breeding methods. Recently, by combing the microspore culture and markerassisted selection, Wang's group at the Oil Crops Research Institute of the Chinese Academy of Agricultural Science used four special aforementioned resources (zy036, 6F313, 61616 , and 61218) to create five new strains with oil contents of $60 \%$, among which YN171 has an oil content of up to $64.8 \%{ }^{[5]}$, a new world record.

$\mathrm{Hu}$ et al. ${ }^{[5]}$ conducted anatomical analysis on the seeds with different oil contents, and proposed a forecasting model of rapeseed oil content. Oil content $=$ cotyledon ratio $\times$ oil body organelles ratio in cotyledon cell + radicle ratio $\times$ oil body organelles ratio in radicle cell $+1 / 3 \times$ seed coat ratio $\times$ oil body organelles ratio in aleurone cells. According to this formula, if the maximum values of the various components of rapeseed currently observed were considered the predicted oil content could be increased to $75 \%$, indicating further potential for improvement in rapeseed oil content.

\subsection{Breeding of high oil content B. napus cultivars}

If high oil varieties are to be practical, they must also have other excellent agronomic traits. Until now, high oil breeding has experienced two phases: The first phase was to identify high oil content cultivars with low erucic acid and low glucosinolate contents, high levels of which are harmful to human health), and the second phase was high oil content taking into account other characteristics such as high yield and other desirable agronomic traits. For phaseI, Canada and Europe achieved the goal much earlier. Well known varieties includs the Canadian double low varieties Zephyr and Midas both with oil contents exceeding $50 \%{ }^{[83]}$, and French double low variety Major with an oil content over $50 \%{ }^{[76]}$. Since the early 1980 s, high oil rapeseed breeding work in China has included consideration of erucic acid and glucosinolate contents. After 20 years, high oil rapeseed varieties in China have basically achieved the double low character, and average oil content in varieties has been improved by $2 \%-3 \%$ over nearly 10 years, from $40.5 \%$ to $43 \%{ }^{[23,84]}$.

Current breeding objectives for high oil rapeseed varieties are currently in the second phase, which takes into account high oil content and high yield combined with desirable agronomic traits including Sclerotinia resistance, pod shattering resistance, and lodging resistance. Good progress has been made; 24 high oil containing varieties were identified during the national validation of winter rapeseed varieties in China during 2001-2006. Among them, Zhongshuang 9 was obtained from a multiple cross, microspore culture, and different generations screening for target traits. The integrated traits include yield, resistance, and quality to achieve rapid pyramiding of multiple target traits with good qualities such as high oil content, high yield, high disease resistance, high lodging resistance, high protein content, low erucic acid, and low sulfur glucoside content. During 2007-2010, China produced 44 winter rapeseed varieties with high oil content. Among them, Zhongshuang 11 was the first released OP variety with oil content $>49 \%$; it combines outstanding traits such as high oil content, strong shattering resistance, lodging resistance and resistant to Sclerotinia. Zhongshuang 11 overcame the contradictions between phenotypes of high oil content and yields, resistance traits through combining approaches such as microspore culture and marker assistant selection.

\section{Conclusions and future perspectives}

Although rapeseed oil content breeding has made good progress worldwide in the past ten years, there is still potential for further improvement. Synchronous improvement of multiple traits is the current trend for high oil breeding. The completion of rapeseed genome sequencing projects will further help in identifying and isolating the corresponding genes from oil trait QTLs. Moreover, the availability of NGS and SNP arrays will accelerate research on molecular regulatory mechanisms that may help to increase rapeseed oil content. Genetic engineering, molecular marker technology combined with a conventional directional selection strategy will be the trend in breeding high oil content rapeseed.

Acknowledgements This study was supported by the National Key Basic Research Program of China (2015CB150200), the National High Technology Research and Development Program of China (2013AA102602), and the Industry Technology System of B. napus in China. We wish to express our thanks to Dr Ming Zheng for his contributions to the model figure.

Compliance with ethics guidelines The authors Wei Hua, Jing Liu, and Hanzhong Wang declare that they have not conflicts of interest or financial conflicts to disclose.

This article is a review and does not contain any studies with human or animal subjects performed by any of the authors.

\section{References}

1. Shang G X. Study on inheritance and NIRS model establishing of high oleic acid content in Brassica napus L. Dissertation for the Master Degree. Chongqing: Southwestern University, 2010 (in Chinese)

2. Wang H Z. Review and future development of rapeseed industry in China. Chinese Journal of Oil Crop Sciences, 2010, 32(2): 300-302 
(in Chinese)

3. Li Y C, Hu Q, Mei D S, Li Y D, Xu Y S. Theory and practice for the development of canola varieties with high oil content. Chinese Journal of Oil Crop Sciences, 2006, 28(1): 92-96 (in Chinese)

4. Wang H Z. Studies on microspore culture of hybrid parents in Brassica napus. Chinese Journal of Oil Crop Sciences, 2004, 26(1): 98-101 (in Chinese)

5. Hu Z Y, Hua W, Zhang L, Deng L B, Wang X F, Liu G H, Hao W J, Wang H Z. Seed structure characteristics to form ultrahigh oil content in rapeseed. PLoS ONE, 2013, 8(4): e62099

6. Gan G X, Lin S C. Rapeseed oil content and high oil content breeding. Seed, 1997, 1: 31-33

7. Wang T. Genetic and heterosis of rapeseed oil content. Journal of Guizhou Agricultural Sciences, 1992, 6: 37-42 (in Chinese)

8. Wu J G, Shi C H, Zhang H Z. Partitioning genetic effects due to embryo,cytoplasm and maternal parent for oil content in oilseed rape (Brassica napus L.). Genetics and Molecular Biology, 2006, 29 (3): 533-538

9. Wang X F, Liu G H, Yang Q, Hua W, Liu J, Wang H Z. Genetic analysis on oil content in rapeseed Brassica napus L. Euphytica, 2010, 173(1): 17-24

10. Weselake R J. Storage lipids. In: Murphy D J, editor. Plant lipids: biology, utilization and manipulation. Oxford: Blackwell Publishing, 2005, 162-221

11. Lung S C, Weselake R J. Diacylglycerol acyltransferase: a key mediator of plant triacylglycerol synthesis. Lipids, 2006, 41(12): 1073-1088

12. Snyder C L, Yurchenko O P, Siloto R M, Chen X, Liu Q, Mietkiewska E, Weselake R J. Acyltransferase action in the modification of seed oil biosynthesis. New Biotechnology, 2009, 26(1-2): 11-16

13. Roesler K, Shintani D, Savage L, Boddupalli S, Ohlrogge J. Targeting of the Arabidopsis homomeric acetyl-coenzyme A carboxylase to plastids of rapeseeds. Plant Physiology, 1997, 113 (1): $75-81$

14. Vigeolas H, Waldeck P, Zank T, Geigenberger P. Increasing seed oil content in oil-seed rape (Brassica napus L.) by over-expression of a yeast glycerol-3-phosphate dehydrogenase under the control of a seed-specific promoter. Plant Biotechnology Journal, 2007, 5(3): 431-441

15. Jako C, Kumar A, Wei Y, Zou J, Barton D L, Giblin E M, Covello P S, Taylor D C. Seed-specific over-expression of an Arabidopsis cDNA encoding a diacylglycerol acyltransferase enhances seed oil content and seed weight. Plant Physiology, 2001, 126(2): 861-874

16. Taylor D C, Zhang Y, Kumar A, Francis T, Giblin E M, Barton D L, Ferrie J R, Laroche A, Shah S, Zhu W, Snyder C L, Hall L, Rakow G, Harwood J L, Weselake R J. Molecular modification of triacylglycerol accumulation by over-expression of DGAT1 to produce canola with increased seed oil content under field conditions. Botany, 2009, 87(6): 533-543

17. Zheng P, Allen W B, Roesler K, Williams M E, Zhang S, Li J, Glassman K, Ranch J, Nubel D, Solawetz W, Bhattramakki D, Llaca V, Deschamps S, Zhong G Y, Tarczynski M C, Shen B. A phenyalanine in DGAT is a key determinant of oil content and composition in maize. Nature Genetics, 2008, 40(3): 367-372

18. Lardizabal K D, Effertz R, Levering C, Mai J, Pedroso M C, Jury T,
Aasen E, Gruys K, Bennett K. Expression of Umbelopsis ramanniana DGAT2A in seed increases oil in soybean. Plant Physiology, 2008, 148(1): 89-96

19. Jain R K, Coffey M, Lai K, Kumar A, MacKenzie S L. Enhancement of seed oil content by expression of glycerol-3phosphate acyltransferase genes. Biochemical Society Transactions, 2000, 28(6): 958-961

20. Zou J T, Katavic V, Giblin E M, Barton D L, MacKenzie S L, Keller W A, Hu X, Taylor D C. Modification of seed oil content and acyl composition in Brassicaceae by expression of a yeast sn-2 acyltransferase gene. Plant Cell, 1997, 9(6): 909-923

21. Taylor D C, Katavic V, Zou J, MacKenzie S L, Keller W A, An J, Friesen W, Barton D L, Pedersen K K, Michael Giblin E, Ge Y, Dauk M, Sonntag C, Luciw T, Males D. Field-testing of transgenic rapeseed cv. Hero transformed with a yeast sn-2 acyltransferase results in increased oil content, erucic acid content and seed yield. Molecular Breeding, 2001, 8(4): 317-322

22. Weselake R J, Taylor D C, Rahman M H, Shah S, Laroche A, McVetty P B, Harwood J L. Increasing the flow of carbon into seed oil. Biotechnology Advances, 2009, 27(6): 866-878

23. Xu Y L, Guan C Y, Tan T L, Yu L X. Changes of oil content and oil biosynthesis-related enzymes activities and their correlation during seed formation in Brassica napus. Acta Agronomica Sinica, 2008, 34(10): 1854-1857 (in Chinese)

24. Plaxton W C, Podesta F E. The functional organization and control of plant respiration. Critical Reviews in Plant Sciences, 2006, 25(2): 159-198

25. Andre C, Froehlich J E, Moll M R, Benning C. A heteromeric plastidic pyruvate kinase complex involved in seed oil biosynthesis in Arabidopsis. Plant Cell, 2007, 19(6): 2006-2022

26. Zou J T, Qi Q, Katavic V, Marillia E F, Taylor D C. Effects of antisense repression of an Arabidopsis thaliana pyruvate dehydrogenase kinase cDNA on plant development. Plant Molecular Biology, 1999, 41(6): 837-849

27. Marillia E F, Micallef B J, Micallef M, Weninger A, Pedersen K K, Zou J, Taylor D C. Biochemical and physiological studies of Arabidopsis thaliana transgenic lines with repressed expression of the mitochondrial pyruvate dehydrogenase kinase. Journal of Experimental Botany, 2003, 54(381): 259-270

28. Wakao S, Andre C, Benning C. Functional analyses of cytosolic glucose-6-phosphate dehydrogenases and their contribution to seed oil accumulation in Arabidopsis. Plant Physiology, 2008, 146(1): 277-288

29. Santos-Mendoza M, Dubreucq B, Baud S, Parcy F, Caboche M, Lepiniec L. Deciphering gene regulatory networks that control seed development and maturation in Arabidopsis. Plant Journal, 2008, 54(4): 608-620

30. Focks N, Benning C. Wrinkled1: a novel, low-seed-oil mutant of Arabidopsis with a deficiency in the seed-specific regulation of carbohydrate metabolism. Plant Physiology, 1998, 118(1): 91-101

31. Baud S Ã, Wuillã "me S, To A, Rochat C, Lepiniec L Ã. Role of WRINKLED1 in the transcriptional regulation of glycolytic and fatty acid biosynthetic genes in Arabidopsis. Plant Journal, 2009, 60(6): 933-947

32. Liu J, Hua W, Zhan G, Wei F, Wang X, Liu G, Wang H. Increasing seed mass and oil content in transgenic Arabidopsis by the 
overexpression of wril-like gene from Brassica napus. Plant Physiology and Biochemistry, 2010, 48(1): 9-15

33. Lotan T, Ohto M, Yee K M, West M A L, Lo R, Kwong R W, Yamagishi K, Fischer R L, Goldberg R B, Harada J J. Arabidopsis LEAFY COTYLEDON1 is sufficient to induce embryo development in vegetative cells. Cell, 1998, 93(7): 1195-1205

34. Mu J, Tan H, Zheng Q, Fu F, Liang Y, Zhang J, Yang X, Wang T, Chong K, Wang X, Zuo J. LEAFY COTYLEDON1 is a key regulator of fatty acid biosynthesis in Arabidopsis. Plant Physiology, 2008, 148(2): 1042-1054

35. Tan H, Yang X, Zhang F, Zheng X, Qu C, Mu J, Fu F, Li J, Guan R, Zhang H, Wang G, Zuo J. Enhanced seed oil production in canola by conditional expression of Brassica napus LEAFY COTYLEDON1 and LEC1-LIKE in developing seeds. Plant Physiology, 2011, 156 (3): $1577-1588$

36. Stone S L, Braybrook S A, Paula S L, Kwong L W, Meuser J, Pelletier J, Hsieh T, Fischer R L, Goldberg R B, Harada J J. Arabidopsis LEAFY COTYLEDON2 induces maturation traits and auxin activity: implications for somatic embryogenesis. Proceedings of the National Academy of Sciences of the United States of America, 2008, 105(8): 3151-3156

37. Shen B, Allen W B, Zheng P Z, Li C J, Glassman K, Ranch J, Nubel D, Tarczynski M C. Expression of ZmLECl and ZmWRI1 increases seed oil production in maize. Plant Physiology, 2010, 153(3): 980987

38. Kim H U, Jung S J, Lee K R, Kim E H, Lee S M, Roh K H, Kim J B. Ectopic overexpression of castor bean LEAFY COTYLEDON2 (LEC2) in Arabidopsis triggers the expression of genes that encode regulators of seed maturation and oil body proteins in vegetative tissues. FEBS Open Bio, 2014, 4(1): 25-32

39. Kagaya Y, Toyoshima R, Okuda R, Usui H, Yamamoto A, Hattori T. LEAFY COTYLEDON1 controls seed storage protein genes through its regulation of FUSCA3 and ABSCISIC ACID INSENSITIVE3. Plant \& Cell Physiology, 2005, 46(3): 399-406

40. Wang Z, Chen M, Chen T, Xuan L, Li Z, Du X, Zhou L, Zhang G, Jiang L. TRANSPARENT TESTA2 regulates embryonic fatty acid biosynthesis by targeting FUSCA3 during the early developmental stage of Arabidopsis seeds. Plant Journal, 2014, 77(5): 757-769

41. Jofuku K D, Omidyar P K, Gee Z, Okamuro J K. Control of seed mass and seed yield by the floral homeotic gene APETALA2. Proceedings of the National Academy of Sciences of the United States of America, 2005, 102(8): 3117-3122

42. Adamski N M, Anastasiou E, Eriksson S, O’Neill C M, Lenhard M. Local maternal control of seed size by KLUH/CYP78A5-dependent growth signaling. Proceedings of the National Academy of Sciences of the United States of America, 2009, 106(47): 20115-20120

43. Chen M X, Xuan L J, Wang Z, Zhou L H, Li Z L, Du X, Ali E, Zhang G P, Jiang L X. TRANSPARENT TESTA 8 inhibits seed fatty acid accumulation by targeting several seed development regulators in Arabidopsis. Plant Physiology, 2014, 165(2): 905-916

44. Liu J, Hua W, Yang H L, Zhan G M, Li R J, Deng L B, Wang X F, Liu G H, Wang H Z. The BnGRF2 gene (GRF2-like gene from Brassica napus) enhances seed oil production through regulating cell number and plant photosynthesis. Journal of Experimental Botany, 2012, 63(10): 3727-3740

45. Hao W J. Molecular mechanism of cytoplasmic effects on oil content in Brassica Napus. Dissertation for the Doctoral Degree. Wuhan: Oil Crops Research Institute, Chinese Academy of Agricultural Sciences, 2014 (in Chinese)

46. Roach D A, Wulff R D. Maternal effects in plant. Annual Review of Ecology and Systematics, 1987, 18(1): 209-235

47. King S P, Lunn J E, Furbank R T. Carbohydrate content and enzyme metabolism in developing canola siliques. Plant Physiology, 1997, 114(1): 153-160

48. Bennett E J, Roberts J A, Wagstaff C. The role of the pod in seed development: strategies for manipulating yield. New Phytologist, 2011, 190(4): 838-853

49. Hua W, Li R J, Zhan G M, Liu J, Li J, Wang X F, Liu G H, Wang H Z. Maternal control of seed oil content in Brassica napus: the role of silique wall photosynthesis. Plant Journal, 2012, 69(3): 432-444

50. Cheng W H, Taliercio E W, Chourey P S. The miniature1 seed locus of maize encodes a cell wall invertase required for normal development of endosperm and maternal cells in the pedicel. Plant Cell, 1996, 8(6): 971-983

51. Li L, Zhao Y, McCaig B C, Wingerd B A, Wang J, Whalon M E, Pichersky E, Howe G A. The tomato homolog of CORONATINE INSENSITIVE1 is required for the maternal control of seed maturation, jasmonate signaled defense responses, and glandular trichome development. Plant Cell, 2004, 16(1): 126-143

52. Maitz M, Santandrea G, Zhang Z, Lal S, Hannah L C, Salamini F, Thompson R D. $r g f 1$, a mutation reducing grain filling in maize through effects on basal endosperm and pedicel development. Plant Journal, 2000, 23(1): 29-42

53. Ohto M, Floyd S K, Fischer R L, Goldberg R B, Harada J J. Effect of APETALA2 on embryo, endosperm, and seed coat development determine seed size in Arabidopsis. Sexual Plant Reproduction, 2009, 22(4): 277-289

54. Liu J, Hua W, Yang H L, Guo T T, Sun X C, Wang X F, Liu G H, Wang H Z. Effects of specific organs on seed oil accumulation in Brassica napus L. Plant Science, 2014, 227(5): 60-68

55. Hao W J, Fan S, Hua W, Wang H Z. Effective extraction and assembly methods for simultaneously obtaining plastid and Mitochondrial Genomes. PLoS ONE, 2014, 9(9): e108291

56. Ecke W, Uzunova M, Wiessleder K. Mapping the genome of rapeseed (Brassica napus L.). II. Localisation of genes controlling erucic acid synthesis and seed oil content. Theoretical and Applied Genetics, 1995, 91(6-7): 972-977

57. Burns M J, Barnes S R, Bowman J G, Clarke M H E, Werner C P, Kearsey M J. QTL analysis of an intervarietal set of substitution lines in Brassica napus: (i) Seed oil content and fatty acid composition. Heredity, 2003, 90(1): 39-48

58. Qiu D, Morgan C, Shi J, Long Y, Liu J, Li R, Zhuang X, Wang Y, Tan X, Dietrich E, Weihmann T, Everett C, Vanstraelen S, Beckett P, Fraser F, Trick M, Barnes S, Wilmer J, Schmidt R, Li J, Li D, Meng J, Bancroft I. A comparative linkage map of oilseed rape and its use for QTL analysis of seed oil and erucic acid content. Theoretical and Applied Genetics, 2006, 114(1): 67-80

59. Delourme R, Falentin C, Huteau V, Clouet V, Horvais R, Gandon B, Specel S, Hanneton L, Dheu J E, Deschamps M, Margale E, Vincourt P, Renard M. Genetic control of oil content in oilseed rape (Brassica napus L.). Theoretical and Applied Genetics, 2006, 113 (7): 1331-1345 
60. Zhao J Y, Becker H C, Zhang D Q, Zhang Y F, Ecke W. Oil content in a European $\times$ Chinese rapeseed population: QTL with additive and epistatic effects and their genotype-environment interactions. Crop Science, 2005, 45(1): 51-59

61. Zhao J Y, Becker H C, Zhang D Q, Zhang Y F, Ecke W. Conditional QTL mapping of oil content in rapeseed with respect to protein content and traits related to plant development and grain yield. Theoretical and Applied Genetics, 2006, 113(1): 33-38

62. Zhao J, Huang J, Chen F, Xu F, Ni X Y, Xu H M, Wang Y L, Jiang C C, Wang H, Xu A X, Huang R Z, Li D R, Meng J L. Molecular mapping of Arabidopsis thaliana lipid-related orthologous genes in Brassica napus. Theoretical and Applied Genetics, 2012, 124(2): 407-421

63. Jin M Y, Li J N, Fu Y F, Zhang Z S, Zhang X K, Liu L Z. Analysis of the oil content and the hull content in Brassica napus L. Agricultural Sciences in China, 2007, 6(4): 414-421 (in Chinese)

64. Zhang J F, Qi C K, Pu H M, Chen S, Chen F, Gao J Q, Chen X J, Gu $\mathrm{H}, \mathrm{Fu} \mathrm{S} \mathrm{Z}$. Inheritance and QTL identification of oil content in rapeseed Brassica napus L. Acta Agronomica Sinica, 2007, 33(9): 1495-1501 (in Chinese)

65. Yan X, Li J, Fu F, Jin M, Chen L, Liu Z. Co-location of seed oil content, seed hull content and seed coat color QTL in three different environments in Brassica napus L. Euphytica, 2009, 170(3): 355 364

66. Chen G, Geng J, Rahman M, Liu X, Tu J, Fu T D, Li G Y, McVetty P B E, Tahir M. Identification of QTL for oil content, seed yield, and flowering time in oilseed rape (Brassica napus). Euphytica, 2010, 175(2): 161-174

67. Zou J, Jiang C, Cao Z, Li R, Long Y, Chen S, Meng J. Association mapping of seed oil content in different Brassica napus populations and its coincidence with QTL identified from linkage mapping. Genome, 2010, 53: 908-916

68. Sun Z Y, Cheng S, Wang J B, Huang J X, Chen F, Ni X Y, Zhao J Y. Validation of QTL for oil content in a population of worldwide rapeseed cultivars by association analysis. Scientia Agricultura Sinica, 2012, 45(19): 3921-3931 (in Chinese)

69. Sun M Y, Hua W, Liu J, Huang S M, Wang X F, Liu G H, Wang H Z. Design of new genome- and gene-sourced primers and identification of QTL for seed oil content in a specially high-oil Brassica napus cultivar. PLoS ONE, 2012, 7(10): e47037

70. Sun F, Liu J, Sun X, Wang X, Liu S, Wang H, Hua W. Identification of QTL for seed oil content in high-oil Brassica napus cultivars. Hefei: Plant genomics in China XV, 2014, 99

71. Li F, Chen B Y, Xu K, Wu J F, Song W L, Bancroft I, Harper A L, Trick M, Liu S Y, Gao G Z, Wang N, Yan G X, Qiao J W, Li J, Li H, Xiao X, Zhang T Y, Wu X M. Genome-wide wide association association study study dissects the genetic architecture of seed weight and seed quality in rapeseed (Brassica napus L.). DNA Research, 2014, 21(4): 355-367

72. Li Z F, Xiang J B. Analysis on grey correlative degree of the oil content in rape seed and yield traits. Journal of Mianyang College of Economy \& Technology, 1999, 16(1): 16-19 (in Chinese)

73. Sun M Y. Mapping of QTLs and screening of candidate genes for oil content in Brassica napus. Dissertation for the Doctoral Degree. Wuhan: Oil Crops Research Institute, Chinese Academy of Agricultural Sciences, 2012 (in Chinese)

74. Yang X D. The study on the relationship between lignin biosynthesis manipulation and Brassica napus' resistance to Sclerotinia sclerotiorum and lodging. Dissertation for the Doctoral Degree. Wuhan: Oil Crops Research Institute, Chinese Academy of Agricultural Sciences, 2006 (in Chinese)

75. Rahman H, Harwood J, Weselake R. Increasing seed oil content in Brassica species through breeding and biotechnology. Lipid Technology, 2013, 25(8): 182-185

76. Baud S, Lepiniec L. Physiological and developmental regulation of seed oil production. Progress in Lipid Research, 2010, 49(3): 235249

77. Vuorinen A L, Kalpio M, Linderborg K M, Kortesniemi M, Lehto K, Niemi J, Yang B, Kallio H P. Coordinate changes in gene expression and triacylglycerol composition in the developing seeds of oilseed rape (Brassica napus) and turnip rape (Brassica rapa). Food Chemistry, 2014, 145(4): 664-673

78. Yu E, Fan C C, Yang Q Y, Li X D, Wan B X, Dong Y N, Wang X M, Zhou Y M. Identification of heat responsive genes in Brassica napus siliques at the seed-filling stage through transcriptional profiling. PLoS ONE, 2014, 9(7): e101914

79. Fu T D. Improvement of rapeseed varities. Crop Research, 2007, (3): 159-162

80. Fu S H, Zhang J F, Qi C K, Pu H M, Gao Q J, Chen X J, Chen F. Breeding for high oil content lines in rapeseed (Brassica napus L.). Chinese Journal of Oil Crop Sciences, 2008, 30(3): 279-283 (in Chinese)

81. Zhu J C, Zhang S F, Wen Y C, Wang J P, Zhao L, Wang J L, Liu G. Studies on breeding method of the high oil content line T057-7 in Brassica napus. Chinese Agricultural Science Bulletin, 2009, 25 (18): 194-197 (in Chinese)

82. Li D R, Tian J H, Chen W J, Zhang W X, Li Y H, Wang H. Breeding technologies and germplasm innovation on extra-high-oil content in Brassica napus. Acta Agriculturae Boreali-occidentalis Sinica, 2011, 20(12): 83-87 (in Chinese)

83. McVetty P B E, Scarth R, Fernando W G D, Li G, Sun Z, Taylor D, $\mathrm{Tu}$ J, Zelmer C D. Brassica seed quality breeding at the University of Manitoba. In: The 12th international Rapeseed Congress, Wuhan. The Groupe Consultatif International de Recherche sur le Colza (GCIRC) (International Consultative Group of Research on Rapeseed), 2007, 2-4

84. Yu Q Y, Liu F L, Zhang D Q. The evolution analysis of quality and yield characters of new rapeseed lines tested in national winter rapeseed regional experiment in recent decade in China. Chinese Agricultural Science Bulletin, 2010, 26(16): 119-123 (in Chinese) 